\section{EL PERIODISMO Y LA HISTORIA: CHAVES NOGALES Y LA REVOLUCIÓN RUSA}

\author{
Antonio Martínez Illán \\ Universidad de Navarra \\ https://orcid.org/0000-0003-3425-9806 \\ amartinez@unav.es \\ Álvaro Pérez Álvarez \\ Universidad de Montevideo \\ https://orcid.org/ 0000-0002-6936-4887 \\ maperez1@um.edu.uy
}

\begin{abstract}
Cómo citar este artículo/Citation: Martínez Illán, A. y Pérez Álvarez, A. (2019). El periodismo y la historia: Chaves Nogales y la Revolución rusa. Arbor, 195 (792): a510. https://doi. org/10.3989/arbor.2019.792n2011
\end{abstract}

Recibido: 19 marzo 2018. Aceptado: 24 mayo 2018.

RESUMEN: El objetivo de este artículo es mostrar cómo la imagen que dio Manuel Chaves Nogales de la revolución rusa a través de sus artículos en los años treinta, siendo vanguardia del periodismo de entonces, tuvo un sentido histórico. La hipótesis es que el periodismo, informando sobre el presente, puede aportar a los historiadores alguna lección. Para mostrar la conciencia histórica del periodismo de Chaves Nogales se contextualiza al autor entre otros viajeros de la época a la Unión Soviética, se analiza la manera en la que Chaves interpreta las huellas de la revolución en las personas y en su entorno y se relaciona con la microhistoria.

PALABRAS CLAVE: Chaves Nogales; revolución rusa; periodismo; historia; Unión Soviética; Rusia-España.

\section{JOURNALISM AND HISTORY: MANUEL CHAVES NOGALES AND THE RUSSIAN REVOLUTION}

Copyright: (c) 2019 CSIC. Este es un artículo de acceso abierto distribuido bajo los términos de la licencia de uso y distribución Creative Commons Reconocimiento 4.0 Internacional (CC BY 4.0).
ABSTRACT: The objective of this article is to show how the picture Manuel Chaves Nogales presented of the Russian Revolution through his articles in the 30 's, the vanguard of journalism of that time, had a historical meaning. The hypothesis proposed is that journalism reporting on the present can also provide historians with some lessons. To show the historical awareness of Chaves Nogales' journalism, the author is contextualized among other travelers to the Soviet Union of that time. The way in which Chaves interprets the traces of the Revolution in people and their environment and how these relate to microhistory are studied.

KEYWORDS: Chaves Nogales; Russian revolution; journalism; history; Soviet Union; Russia-Spain. 


\section{LOS VIAJES A RUSIA Y LO QUE SE ESPERABA VER}

Cuando Lippmann y Merz (1920) analizan la cobertura por parte del New York Times de la revolución rusa en los años 20 afirman: "news about Russia is a case of seeing not what was, but what men wanted to see" (p. 3). Cuando el periodista sevillano Manuel Chaves Nogales visitó ese país, buscaba observar en qué se había convertido la revolución en 1928 y contarlo mediante el periodismo. Un siglo después de la revolución, cuando la tecnología ha cambiado el periodismo y la labor de informarse es entendida en muchos casos como ratificación de ideas previas, la manera en que se desarrolla el periodismo de Chaves ofrece algunas lecciones sobre cómo informar y entender un acontecimiento histórico como la revolución rusa y este artículo propone precisamente mostrar esas enseñanzas a través del análisis de sus textos periodísticos sobre Rusia.

En los años 20 y 30 del siglo pasado la revolución rusa fue un tema tratado por viajeros, intelectuales y periodistas entre la idealización y el rechazo. Cruz y Pérez Ledesma (1997) describen "la lucha sin cuartel que se produce en los medios de comunicación en España por imponer una imagen de la Unión Soviética" (p. 273) en esa época. Era difícil no caer en la seducción del sueño de un nuevo orden o bien en la condena de la revolución de octubre como un fracaso, asociándola con el apocalipsis. García-Alix (2003) describe la admiración que nace en esos años:

"Surge entonces una profunda corriente de admiración y simpatía por la revolución soviética, que penetrará sobre todo en los medios obreros e intelectuales. Asistimos a una explosión de nuevas editoriales como Cenit, Ulises, Oriente y Fénix, que difunden en ediciones asequibles las grandes obras de la literatura soviética, así como sus más recientes creaciones. El clima de entusiasmo e interés propiciará una avalancha de viajes. Todos quieren ver la nueva Rusia, adonde viajan Margarita Nelken, Álvarez del Vayo, Ramón J. Sender, Manuel Chaves Nogales, Josep Pla, Félix Ros" (p. 76).

Estos viajes, a partir de la mitad de los años 20, son denominados romerías por Giménez Caballero (1928). Sinclair (2009) analiza a los viajeros españoles de los años 20 señalando que todos cuentan aquello de lo que han sido testigos y, en el caso de Chaves e Hidalgo, insisten en que son visitantes de clase media (p. 124). Cortés (2006) explica que la Unión Soviética se puso de moda en los años posteriores a 1928 y a esta moda se sumaron algunos periodistas, entre los que menciona a Chaves (p. 79).
Desde España viajaron sobre todo políticos -los socialistas, por ejemplo, viajaban auspiciados por la Internacional Socialista- y periodistas. Así, entre los políticos, Fernando de los Ríos publicó en 1921 Mi viaje a la Rusia sovietista; el comunista asturiano Isidro Acevedo Impresiones de un viaje a Rusia, y el anarquista y delegado de la CNT Ángel Pestaña lanzó en 1924 otros dos libros. El relato periodístico incluyó tres libros de Álvarez del Vayo: en 1926 La nueva Rusia, en 1928 La senda roja, y Rusia a los doce años en 1929. Con él viajó otro corresponsal de El Sol, Ricardo Baeza, que publicó Bajo el signo de Clío. Itinerario en 1931. Josep Plá publicó en 1925 Notícies de la URSS (Una encuesta periodística); Sofía Casanova De Rusia. Amores y confidencias (1927) -entre otros muchos textos (Ochoa Crespo, 2016)-; el socialista Rodolfo Llopis iba a publicar la crónica de su viaje en El Sol pero la censura lo impidió y publicó el libro Cómo se forja un pueblo. La Rusia que yo he visto (1929) y León Villanúa escribió La Rusia inquietante (1931). El viaje de Villanúa comienza con un encuentro con una bolchevique en el Prado con quien habla precisamente sobre las visitas de extranjeros a Rusia:

"Pero han ido gentes llenas de prejuicios, profesores de universidad o jefes de partidos comunistas extranjeros, periodistas que iban a decir que todo estaba muy bien o muy mal, según les habían pagado; españoles no ha ido nadie.

\section{[...] -iOh! ... Y periodistas han ido pocos.}

-Yo no conozco a ninguno, fuera de Álvarez del Vayo, Chaves y Llopis" (Villanúa, 1931, pp. 16-17).

Navarra (2015) califica al grupo de viajeros anteriores a la guerra civil no militantes o críticos con el sistema soviético como "socialistas y republicanos: la respuesta humanística" (pp. 132-145). En el grupo incluye a periodistas y políticos. Además de los ya mencionados señala el relato de Llopis, de Zugazagoitia, Anguiano y Amado Blanco. De entre esas visiones españolas el relato de Chaves Nogales le resulta el más acabado. Para él, Chaves es "un olfateador, no un impresionista ni un político profesional. Un verdadero reportero que busca historia" (Navarra, 2015, p. 134). De entre todos los relatos de viajeros aquí se toma como objeto de estudio el de Chaves por dos motivos. En primer lugar, por lo que señala Navarra: este relato del viaje a la URSS tiene un fin primero que es periodístico. Chaves Nogales no pertenecía a la Internacional Socialista y viajó a la Unión Soviética en 1928 como corresponsal del Heraldo de Madrid. Y en segundo lugar, porque todos estos viajeros com- 
partían la conciencia histórica que suponía hablar de la Unión Soviética como testigos en Occidente. El nacionalsocialismo en Europa y la situación en España dependían en parte de lo que sucediera en la URSS y de los debates de la Comintern. El caso de Chaves resulta interesante para lo que aquí se propone porque continuó escribiendo sobre la revolución durante la década siguiente y desde fuera de la URSS. Chaves intentó contar lo que fueron aquellos meses recomponiendo el relato a partir de la memoria de sus protagonistas, perdedores o testigos exiliados en París y a quienes les tocó la revolución en Petrogrado y la posterior guerra civil.

En concreto publicó tres libros periodísticos sobre este tema. En el primero recoge para los lectores de Heraldo de Madrid su visión de la Rusia soviética durante su viaje a la URSS en 1928 -agonizando la dictadura de Primo de Rivera- a partir de testimonios de los ciudadanos soviéticos y de su propia observación. Estas crónicas y reportajes formarían luego La vuelta a Europa en avión. Un pequeño burgués en la Rusia roja (1929); en segundo lugar, habló de Rusia en las crónicas para el diario Ahora desde París donde recogió la vida de los exiliados zaristas en Lo que ha quedado del imperio de los zares (2011); y por último, contó la revolución rusa a través del testimonio del bailaor flamenco Juan Martínez en El maestro Juan Martínez que estaba allí (1934/2007). Si bien escribió también una novela sobre las relaciones afectivas en el comunismo -La bolchevique enamorada. El amor en la Rusia roja (1930)-, nos interesa aquí detenernos en el Chaves periodista y en su crónica de la revolución. Las tres obras analizadas fueron recopiladas por vez primera en 1993. Ese año la Diputación de Sevilla publicó la Obra narrativa completa de Manuel Chaves Nogales, gracias a una edición realizada por María Isabel Cintas. A partir de ese trabajo se realizaron todas las ediciones posteriores de las distintas editoriales. Cintas es también la responsable de editar por primera vez toda la obra conocida de Chaves no solo en los dos tomos de la Obra narrativa completa (1993 y 2009b), sino también con los tres tomos de la Obra periodística (2001 y 2013).

\section{LA FUNCIÓN DEL PERIODISTA}

La vuelta a Europa en avión. Un pequeño burgués en la Rusia roja recoge las crónicas aparecidas de manera original en Heraldo de Madrid sobre el viaje de Chaves desde Madrid a Bakú. Las veintiséis crónicas comenzaron a publicarse el 6 de agosto de 1928 y finalizaron el 24 de octubre. A partir de entonces hasta febrero de 1929 aparecieron también en La Nación (Buenos Aires). La obra se publicó posteriormente, el 15 de abril de 1929, en la editorial Mundo Latino que fue la que añadió el subtítulo Un pequeño burgués en la Rusia roja a los textos periodísticos originales.

Para Chaves el periodismo supone un punto de vista desde el que cuenta la realidad. En el proemio al libro deja claro cuál es su función:

“Interpreto, según mi temperamento, el panorama espiritual de las tierras que he cruzado" (Chaves Nogales, 2001, p. 22).

El subtítulo del libro, Un pequeño burgués en la Rusia roja, aclara la posición desde donde observa, algo a lo que vuelve:

\footnotetext{
"Uno mira estas cosas fatalmente desde un punto de vista burgués" (Chaves Nogales, 2001, p. 136).
}

Chaves dedicó a Rusia dieciséis de las veintiséis entregas originales y once de los diecinueve capítulos del libro. Cuando este salió publicado, varió la distribución original, renombró los títulos, amplió ciertas ideas, reorganizó algunos pasajes y mostró otros que, a causa de la censura, no pudo publicar en la prensa. Así, incluyó una entrevista a Ramón Casanellas -uno de los participantes en el asesinato del presidente del consejo de ministros, Eduardo Dato, en 1921- y un nuevo capítulo dedicado a la vida soviética (Cintas Guillén, 2001b, pp. 48-56).

Las crónicas de Chaves se abren con una cita de Tiutchev: "Rusia: Nunca sabrá ver el ojo soberbio del extranjero el tesoro que hay escondido en tu humilde pobreza" (Chaves Nogales, 2001, p. 107), otra declaración que deja claros desde el comienzo los límites del periodismo que él practica:

"Contar y andar es la función del periodista. Araquistáin, en su viaje a las escuelas de España, Álvarez del Vayo, en sus frecuentes excursiones por el panorama espiritual de Centroeuropa, y alguno otro son claros ejemplos de este periodismo nuevo, discreto, civilizado, que no reclama la atención del lector sino es con un motivo: contarle algo, informarle de algo" (Chaves Nogales, 2001, p. 20).

Chaves entiende que el periodista -citando a Keyserling-, tiene como función ser intermediario espiritual, por eso él intenta ver "el alma rusa" a través de sus ojos de extranjero, en la imagen de los mujik, las isbas o las iglesias:

"Las iglesias van jalonando todo el campo. ¿Se comprende ahora la fuerza indestructible que tiene 
la religión entre esta gente, fuerza que ni siquiera la gran conmoción del comunismo ha podido neutralizar?" (Chaves Nogales, 2001, p. 117).

Lo que ve se convierte en indicio de lo que espera ver. Así, en "Paseos por Moscú" comienza diciendo:

“Apenas se pone el pie en Moscú, se tiene súbitamente [...] la sensación de que aquello ha sido arrasado por la revolución (...). El bolchevique ha querido hacer tabla rasa de todo lo anterior. Esto donde se ve bien es en Moscú" (Chaves Nogales, 2001, p. 122).

Después, cuenta la historia de la ciudad y sus monumentos, pero de entrada deja claro cuál es el prisma a través del cual contempla la capital. En Leningrado, al burlar a un guardia del GPU para visitar a un partidario de Trotsky, escribe:

"Leningrado conserva todavía la emoción de la clandestinidad revolucionaria" (Chaves Nogales, 2001, p. 252).

Es una impresión, pero contiene el principio de su interpretación de la realidad que va buscando: qué queda de la revolución. Igual sucede con aquellos a quienes entrevista o con las fuentes a las que da voz en el reportaje. Busca indicios que muestren cómo la revolución ha cambiado la vida. Por ejemplo, "un intelectual, moscovita de adopción, de origen indio que lleva muchos años en Rusia" expresa la misma idea que ronda a Chaves, la de que el espíritu de las gentes ha cambiado:

"La revolución ha sacado de sus goznes las hojas de las contraventanas [...], ha metiendo tres familias -tres extrañas familias- en lo que antes era cochera de los señores. Pero todo sigue exteriormente igual. Dentro, en las estrechas habitaciones, hay hacinada una humanidad conmovida por la revolución que intenta vanamente acomodarse a las exigencias de los tiempos nuevos. En cada habitación, una familia; en cada familia, una guerra viva. El padre es nepman, el hijo comunista; la madre va todos los días a pedir al pope consuelo para sus tristezas.

Todo esto por dentro. Afuera siguen brillando las cúpulas doradas de las iglesias. [...]. El espíritu de las gentes ha cambiado, pero el espíritu de la vieja ciudad subsiste después de haber sido arrasada" (Chaves Nogales, 2001, pp. 124-125).

Con el nervio y la urgencia del periodismo, este pasaje muestra una de las genialidades de Chaves: intuir en algunos indicios la vida que llevan los moscovitas y el cambio social provocado por la revolución. La paradoja dentro/fuera, viejo/nuevo, a partir de la impre- sión visual de las fachadas, da lugar a una imagen de lo que va queriendo ver, el cambio o no que la revolución ha producido. Así también lo hará hablando de los carteles de los líderes:

“Todo Moscú está lleno de la iconografía de la revolución [...]. No hay modo, sin embargo, de encontrar un retrato de Trotsky en toda Rusia" (Chaves Nogales, 2001, p. 205).

Esa impresión primera en casi todo lo que mira busca la huella de la revolución y su envés o contrapartida y ese es uno de los temas que se mantendrá en las crónicas.

Como todos los viajeros a Rusia, también Chaves buscaba ver en qué se había convertido la revolución. El relato de Chaves da una imagen de una revolución disecada en la que los revolucionarios habían servido para elaborar el mito, pero ya no contaban, y así lo muestra en el retrato de Kalinin o en la búsqueda de Trotsky. Conocer la personalidad de Trotsky era una de las cuestiones que más interesaban a Chaves (2001, p. 206). No consiguió entrevistarse con Trotsky pero elabora un perfil de su ausencia en Alma-Ata, habla con colaboradores, y escribe, adelantándose al asesinato y a los pensamientos de Stalin:

"Trotsky es de esa clase de hombres que sólo pueden inutilizarse con la muerte" (Chaves Nogales, 2001, p. 208).

Sobre el debate de la II Internacional Socialista, de la doctrina de Stalin del comunismo en un solo país que había dado al destierro de Trotsky, diagnostica:

"Para mantener en toda su pureza el ideal comunista, sería preciso hacer una revolución cada cinco años. Esta es la gran tragedia del bolchevismo, insoluble mientras no se realice el sueño de la revolución mundial" (Chaves Nogales, 2001, p. 214).

Chaves tiene experiencia con la GPU y con la censura pero escribe:

“Deliberadamente me he limitado, en la reseña de mi viaje por el territorio ruso, a exponer, desnudos de artificio, los pequeños hechos de la vida cotidiana que caían bajo mi zona de observación, y he guardado cuidadosamente tanto la documentación oficial, que a manos llenas se me ha ofrecido en Rusia, como cualquier deseo de interpretación personal que pudiera haberme asaltado" (Chaves Nogales, 2001, p. 235).

De nuevo una declaración de intenciones sobre cómo entiende el periodismo y una interpretación de lo que ha supuesto la revolución. Chaves informa de 
aquello que interesa a sus lectores. Para ese público la revolución rusa llevaba a la pregunta sobre si se extendería el sistema soviético por Europa. Las imágenes de la revolución rusa en los primeros años treinta conectaban con las movilizaciones en España y esa conexión aumentaría, a juicio de Cruz y Pérez Ledesma (1997), a partir de 1936 (p. 294). Chaves escribe para esa población, por eso resume así:

\begin{abstract}
"Después de haber recorrido Rusia y de haber buscado afanosamente cuanto en pro o en contra de la revolución se ha escrito, yo me atrevo a creer que la postura del hombre auténticamente civilizado no es la de ser comunista o anticomunista, sino la de estar atento al desenvolvimiento de los hechos [...], sin desechar la posibilidad del alumbramiento de una nueva humanidad, pero sin perder de vista al mismo tiempo que puede haberse errado la senda" (Chaves Nogales, 2001, p. 248).
\end{abstract}

Para Chaves los errores de interpretación sobre la revolución vienen de la propaganda interesada de uno y otro lado. Él, tras un mes como viajero curioso y liberal, se pregunta si se debe aceptar como peaje para una nueva sociedad la dictadura del proletariado:

\footnotetext{
“¿El amor hacia el pueblo debe llevar hasta el extremo de sacrificarlo?" (Chaves Nogales, 2001, p. 258).
}

Y se muestra consciente de que esa imagen de país "todavía desconcertado y ruinoso" (Chaves Nogales, 2001, p. 245) tras once años de la revolución sobre la que elabora su interpretación, puede no ser absolutamente cierta:

\footnotetext{
"De la obra revolucionaria el viajero no ve más que las resquebrajaduras. La reconstrucción de la sociedad deshecha por la revolución sobre la base de la dictadura del proletariado escapa a su comprensión. Y esta reconstrucción, no terminada aún, es, a pesar de todas las fallas, una obra formidable" (Chaves Nogales, 2001, p. 246).
}

Y cuando ya ha salido de la Unión Soviética, escribe:

\footnotetext{
“No quiero tampoco dejarme arrastrar por esta impresión puramente subjetiva de pequeño burgués o intelectual que se siente excluido o, mejor dicho, perseguido por la clase social dominante hoy en Rusia" (Chaves Nogales, 2001, p. 256).
}

Para Peloille (1999) con esta afirmación Chaves hace una distinción implícita entre los regímenes dictatoriales (Rusia y Polonia) y los democráticos (República de Weimar) y entre dos formas de organización social, la del proletariado y la de la burguesía (pp. 122-123). Sánchez Zapatero compara la visión de la Unión Soviética que hay en Chaves con el relato del viaje de Stefan Zweig que recoge en El mundo de ayer. Memorias de un europeo. Los dos viajaron en la segunda mitad de 1928, en estos dos relatos no encuentra juicios interpretativos (Sánchez Zapatero, 2013, p. 113) y estamos de acuerdo en que en el testimonio de los dos escapa a la adhesión o a la crítica de lo que ven.

A juicio de Cintas, La vuelta a Europa en avión conecta con la "novela social", así como con el crecimiento en ese ámbito de los libros de viajes. Muchos de ellos fueron realizados por escritores que habían sido también periodistas y por esta razón se relataban con un tono reportajeado. Más allá del tono en el libro de Chaves se encuentra un juicio premonitorio sobre la revolución y pasarían unas décadas hasta que se escribiera algo al respecto con tanta lucidez. Avilés compara la visión de Chaves con la de Álvarez del Vayo y destaca que:

\footnotetext{
"Varios españoles tuvieron ocasión de hablar a fondo con algunos comunistas disidentes. Especialmente lo hizo Chaves, que se mostró interesado por las tesis de la oposición trotskista, quedó convencido de que Trotski encabezaba a aquellos verdaderos comunistas que se oponían a la conservadora burocracia del partido" (Avilés Farré, 1999, pp. 296-297).
}

Navarra (2015) encuentra similitudes con Dos Passos en el escepticismo de Chaves o en el temor que ve en la gente ante el gobierno (p. 139). Como se ha dicho arriba, este autor incluye a Chaves en el grupo de los humanistas y socialistas. Tal vez lo propio de Chaves Nogales es que escapa a las tipologías. Chaves se separa de un rasgo quizá consustancial al español, la polarización en lo que se mira. Su lucidez la recordaba Trapiello (2010) en Las Armas y las letras (pp. 183-186) refiriéndose al prólogo de $A$ sangre y fuego. Esa clarividencia para interpretar la naturaleza de lo que sucedió en España, sin el prejuicio ideológico, se puede apreciar antes, en lo que escribe sobre Rusia. Como sostiene Muñoz Molina en una entrevista recogida en El hombre que estaba allí:

"Cuando tú lees lo que escribe sobre la Unión Soviética y lees las cosas que escribían intelectuales europeos de primera categoría... A mi él me recuerda una cosa que dice Kessler en sus memorias: "Los que llegábamos del Este de Europa éramos como Casandras a las que nadie escuchaba, nadie quería escuchar". Era así, eso es terrible. Pero no solo basta fijarse y contar lo que se ve. Es que además tienes que intentar que te escuchen" (Suberviola y Torrente, 2013, p. 41). 
Chaves se sale de las categorías ideológicas tan útiles para manuales y para el juicio fácil porque, como señala Muñoz Molina, se alinea en Europa con Joseph Roth, Stefan Zweig, Vasliy Grossmann, George Orwell y Albert Camus, y lo que todos ellos tienen en común es la defensa del humanismo (Suberviola y Torrente, 2013, p. 42).

\section{CONTAR LA MEMORIA DE LOS HECHOS}

Chaves cuenta los hechos de la revolución en 1928, once años después de producirse. Tras regresar de la Unión Soviética y publicar el libro en 1929, Chaves dejó de ser redactor jefe del Heraldo de Madrid y se instaló en París como corresponsal del periódico. Allí fue a buscarlo Luis Montiel para que se sumase al diario Ahora. Sobre el tema ruso siguió publicando en Estampa -revista gráfica propiedad de Montiel y donde había llegado gracias a Vicente Sánchez Ocaña- reportajes fruto del viaje y de La vuelta a Europa en avión como "Moscú se divierte" (1 enero 1929), "Las mujeres en el régimen bolchevique" (23 abril 1929) o "El invierno en Rusia" (19 febrero 1929).

En estos reportajes, como en lo publicado en el $\mathrm{He}$ raldo, Chaves parte de la memoria de alguien que ha vivido la revolución y luego vuelve al presente, para saber qué ha quedado. Si bien encontramos una constante de actualidad, trata de responder a la cuestión sobre el futuro que puede tener la dictadura del proletariado dentro y fuera de Rusia; también realiza una reconstrucción histórica de la revolución. En este punto Chaves lleva a cabo, de acuerdo con Prökker (2012), un "periodismo histórico" (p. 20). Este distingue el periodismo sobre sucesos históricos como el estalinismo con el ejercicio de la historia porque el interés en el periodismo no es el pasado en sí mismo sino en su conexión con el presente.

La memoria que recupera Chaves es la del testigo: él no fabula, escribe a partir de la memoria de quien le cuenta y de otras fuentes con las que se entrevista. $Y$ el retrato que el periodista hace de ellos amplia el testimonio; como en los espacios, también en las personas se aventura a ver las huellas de la revolución. Chaves muestra la sensación que le producen todos estos hombres con descripciones completas, tanto físicas como psicológicas, en las que los rasgos externos que observa en ellos anteceden sus rasgos de carácter. Chaves sigue estando ahí, como narrador dentro de la historia que se hace presente para poner de relieve su papel de periodista directa o indirectamente.
Quizá el momento en el que Chaves juega de manera más evidente el papel de narrador testigo con autoridad para la interpretación está en Lo que ha quedado del imperio de los zares, la serie de 24 reportajes sobre los exiliados blancos en París publicada desde el 27 de enero hasta el 22 de febrero de 1931. Allí, por ejemplo, realiza una descripción completa y significativa de Kerenski en la que mezcla prosopografía y etopeya. Chaves explica que el político ruso era un hombre:

"De ojos claros, alto, desgarbado y de aspecto cansino, que redacta todas las semanas un periodiquito pobre, en un barrio apartado de París. Kerenski da la impresión del que está ausente; tiene algo de sonámbulo, de hombre atento a un rumor distante. Sus ojos, con ese guiño característico del miope sin lentes, miran siempre a un punto lejano. Sus oídos conservan, acaso, el eco de las fusiladas en las calles de Petrogrado, del clamor de las masas revolucionarias o del galope de los jinetes rojos lanzados en su persecución. No sé; pero salta a la vista que es un hombre absorbido por algo que, desde luego, no es el momento de ahora" (Chaves Nogales, 2011, p. 99).

Chaves está dentro del relato en primera persona, como personaje-periodista que observa y apuesta por unos rasgos sobre otros. El porte de Kerenski, su figura, su mirada, reflejan su espíritu, sus preocupaciones y su estado de ánimo. Su forma de actuar en el presente, además, permite a Chaves imaginar cómo pudo vivir los días de la revolución y cómo su forma de ser explica su pasado y su presente con relación al momento histórico:

"Mientras habla, yo escucho un poco sobrecogido sus discretas palabras. Este hombre tiene para mí el prestigio de ser la personificación más completa de una tragedia, vieja como el mundo; la lucha de lo consciente con lo inconsciente. Kerenski es el caso patético del hombre inteligente cogido por el engranaje de hechos monstruosos, superiores a toda previsión intelectual" (Chaves Nogales, 2011, p. 99).

En esta obra, por tanto, el foco se centraba más en las personas que en los pueblos, más allá de que el drama de los exiliados sirviese también a Chaves para referirse a la revolución, a la monarquía zarista y a los nacionalismos periféricos. El diario Ahora necesitaba lectores y el tema de los exiliados rusos era materia ideal para el folletín. Haciendo semblanzas de estos personajes, Chaves cuenta las causas de la revolución según la Rusia blanca. El retrato de Miliukov y de Kerenski cuenta bien el desarrollo de los días de la revolución. Por ejemplo: 


\begin{abstract}
“Apenas entré en el salón de la biblioteca de la Duma me vi envuelto en un torbellino de gente que discutía y gritaba [...]. Cuatro días sin dormir ni comer; cuatro días en los que permanecimos ajenos a todo lo que fuese el peligro que corría nuestra patria, debatiéndose en el caos y la sangre" (Chaves Nogales, 2011, p. 86).

Y más adelante:

"Se le ve con una gran transparencia en aquel caos de la revolución rusa aferrado a sus convicciones intelectuales, sensato, realista, valiente, procurando en vano mantenerse en el fiel de la balanza, queriendo ser ecuánime cuando se habían desatado todas las fuerzas del mal y la ecuanimidad era un delito..." (Chaves Nogales, 2011, p. 99).
\end{abstract}

Es esta manera de enfrentarse a los personajes -conociéndolos cara a cara, dejándoles hablar- la que caracterizará su periodismo y sobre estos testimonios de la revolución construye su impresión de ese momento.

Esta reconstrucción encuentra un paradigma en el relato que Chaves hace del bailaor burgalés Juan Martínez, el protagonista de El maestro Juan Martinez que estaba allí. Chaves lo había conocido en un cabaret de Montmartre y lo incluyó como protagonista en el reportaje "Los flamencos de París", publicado el 18 de marzo de 1930 en Estampa. Este reportaje, que se centraba más en el flamenco que en la vida de los bailaores, da una pista clave para entender al personaje Martínez creado por el periodista. Chaves advertía de que su texto "traducía" el modo de hablar de Martínez, sin renunciar, eso sí, al sentido que le dio el bailaor:

"Él habla a su modo, con sus imágenes castizas plagadas de galicismos; pero a lo largo de su charla internacional, que pondría los nervios de punta a un académico, yo sé que quiere decir eso; y lo traduzco asi" (Chaves Nogales, 2001, p. 178).

Chaves pasa las ideas de Martínez a través del matiz de su mirada, de su interpretación, y es de suponer que esta idea se mantuviese también El maestro Juan Martínez que estaba allí, la obra sobre la trayectoria del bailaor durante la revolución de octubre de 1917, en la que no trata de reproducir la fonética del bailaor, tan solo mantiene algún galicismo. De ahí la importancia de este texto: en él se muestra que para Chaves mostrar quién es un hombre en ocasiones puede significar también interpretar sus palabras sin hacerles perder su significado. Esta labor de traducción, unida al reporterismo, no dista de la visión do- minante en la actualidad a la hora de utilizar la cita directa. Por eso es de agradecer la franqueza de Chaves al admitir que se vio obligado a no mantener la literalidad de las palabras de Martínez pero sin tratar de desdibujar su sentido.

El maestro Juan Martínez que estaba allí se publicó por entregas en la revista Estampa del 17 de marzo al 15 de septiembre de 1934, con ilustraciones de Francisco Rivero Gil (1899-1972), dibujante y caricaturista que se había formado en Sevilla y que desde 1944 vivió en México, donde falleció. Juan Martínez fue testigo directo de los excesos de la guerra y de la revolución. Había viajado a Rusia huyendo de otra guerra, la primera guerra mundial, que estalló cuando se encontraba trabajando en Turquía. En el relato de los hechos Chaves centra el foco en un periodo determinado de la historia, abandona su punto de vista y opta por la historia personal de un testigo para describir el momento histórico de la revolución. Las versiones anteriores de Kerenski o la publicada antes en Estampa se ven superadas. Los hechos históricos quedan como un eco en el relato de Martínez y son rebasados por lo insólito del testigo de la revolución (un bailaor flamenco de Burgos), y por el talento narrativo que la escritura de Chaves le otorga. De acuerdo con Vázquez Liñán (2011), el libro realiza un retrato aterrador de la revolución y de la guerra civil:

\footnotetext{
"se trata de un intento de ver este proceso histórico a través de los ojos de un extranjero [...] y que por lo tanto no tiene a priori preferencias por ninguno de los bandos en conflicto. [...] el reportaje tiene la clara intención de mostrar el horror generado por la revolución, en un momento en el que la salida revolucionaria era una opción propagada por las diferentes fuerzas políticas en España" (p. 66).
}

Como recoge Cintas (2001b), el 16 de febrero de 1934 el diario Ahora, del que era redactor jefe Chaves, se preguntaba qué iba a pasar en España, ante la amenaza de una guerra civil y de una revolución ( $p$. 170). Por eso para Cintas la visión de Chaves "de la tan admirada Revolución rusa debió de ser sorprendente para muchos e inadecuada por inoportuna para los más extremistas de la izquierda" (2001b, p. 173). La distancia del bailaor con los hechos revolucionarios rusos, por no tratarse de su país y porque reconoce abiertamente que no le interesa la política -"yo nunca me he querido meter en política" (Chaves Nogales, 1934/2007, p. 7)-, permitió a Chaves hacer un relato de la violencia que producen los excesos de toda revolución, un reportaje de aquello de lo que quería advertir a los españoles de 1934. 
La primera imagen que tiene Martínez al llegar a Petrogrado en marzo de 1917 es la de un andén vacío y "a la salida de la estación, en una puerta, estaba clavado a bayonetazos el cadáver de un guardia" (Chaves Nogales, 1934/2007, p. 11). La memoria de Juan Martínez recuerda estos hechos violentos, el odio que mueve a las gentes y cómo va salvando la vida en cada una de las encrucijadas que se encuentra:

“iQué odio negro les tenían! Cuarenta mil policías del zar había en Petrogrado el día que estalló la revolución. En ocho días no quedó ni uno. El pueblo tenía tanto rencor contra ellos que cuando yo llegué salían a cazarlos como si fueran conejos. A muchos los clavaron a bayonetazos en las puertas de las casas [...]. En los primeros momentos habían hecho ellos una buena carnicería con los revolucionarios" (Chaves Nogales, 1934/2007, p. 51).

El bailaor sobrevivirá a la revolución de marzo y en la primavera y el verano de 1917 volverá a Moscú por su esposa y juntos regresarán a Petrogrado y después de nuevo a Moscú para ir a Kiev:

"A mí la toma del poder por los bolcheviques, los famosos diez días que conmovieron al mundo, me cogieron en Moscú vestido de corto, bailando en el tablado de un cabaret y bebiendo champaña a todo pasto.

Después de la tournée por Ucrania, y cuando vimos la mala jeta que tenían los campesinos en los últimos tiempos de Kerenski, decidimos refugiarnos en Moscú. Aquellas bestias de campesinos rusos eran capaces de todo" (Chaves Nogales, 1934/2007, p. 70).

Chaves ofrece en cada entrega un relato trabado que sale de la memoria de Martínez y que él parece solo transcribir. El "folletín de la vida de Martínez" -como lo llama- tiene en apariencia una única trama, comprobar cómo se las arregló su protagonista para sobrevivir. Si bien como señala Hermida (2002) "existe una coincidencia general entre los historiadores en el sentido de que los bolcheviques tomaron el poder en la capital con escasísimo derramamiento de sangre" (p. 115), Martínez encontró varios obstáculos para moverse con libertad. Son muchas las escenas en las que su salida de allí se ve frustrada o los momentos en los que parece que su final está cerca.

A lo largo del relato vemos por los ojos de Juan Martínez cómo las gastan los bolcheviques, los blancos y los cosacos. El testimonio de Martínez tiene la virtud de los testigos, creemos en su memoria prodigiosa y en cómo se las ingenia para sobrevivir. Solo parecen importar los hechos: las filas de cadáveres en las calles de San Petersburgo o el vecino ajusticiado porque ante el frío se puso el sobretodo del bando equivocado. La crueldad y la rapiña del hambre no puede contarse y Martínez no lo hace, solo muestra cómo se salvó de ese mundo cuando parecía imposible. El genio narrativo de Martínez -o de Chaves Nogales- tiene su piedra de toque en los relatos que hace de las veces que salva la vida. Es entonces cuando como mucho se permite la viveza del genio hispano, la misma que le salva la vida. La primera de ellas, en Turquía, cuando los alemanes quieren matarlo porque lo toman por espía. Allí será un cuchillo, que siempre lleva consigo, lo que le salva. Casi en cada una de las entregas/capítulos Martínez relata cómo salva la vida, porque deja caer su navaja en un cacheo, porque un coche pasa cuando le van a disparar o porque muestra cómo es un auténtico revolucionario porque tiene las manos callosas por tocar las castañuelas. En la última de ellas, en el barco Anastasia, mientras dispara la policía soviética, logra salir de Odessa con pasaporte italiano.

Chaves no quiere escribir la historia pero la reconstruye a partir de estos testimonios de los testigos, sean los seguidores de Trotski, Kerenski, Miliukov o Martínez, y los intenta ver en el curso de la historia. Las crónicas de la revolución en Chaves están construidas sobre la memoria de testigos. En esta manera de proceder Chaves se adelanta a la microhistoria empleada en la historia y en la etnografía algunas décadas después. La microhistoria, tal como la entiende Ginzburg (1994), quien la resumía a partir de la comparación que hace Kracauer entre la microhistoria/el primer plano en el cine (closeup) y la macrohistoria/tomas largas (long shots). Los primeros planos sobre un hecho histórico permiten contar la historia de una realidad que es discontinua y heterogénea (p. 33).

En El maestro Juan Martínez que estaba allí la vida del protagonista y la historia se entremezclan en el relato. Como explica Cintas (2001b), la obra "es un reportaje novelado de la realidad histórica en el que la vida es capaz de superar a la ficción más disparatada" (p. 174). Se trata de un relato desde el presente sobre el pasado de Martínez, con digresiones e historias dentro de la historia. Desde este punto de vista la estructura se asemeja a la de un perfil periodístico moderno: una escena principal donde se desarrolla la entrevista con escenas que nos llevan a momentos del pasado revolucionario. En conjunto las técnicas utilizadas por 
Chaves se asemejan, como sostiene Pérez Álvarez (2013), a las del nuevo periodismo estadounidense (pp. 81-90).

El primer rasgo que define la caracterización de Juan Martínez es que el personaje toma la voz y muestra en primera persona sus vivencias. La narración delegada en el protagonista no impide que el resultado sea una historia en la que el relato marco, las palabras de Chaves, dan coherencia a la estructura narrativa. Así, tras una breve introducción sobre el lugar en el que vive Martínez, le describe en tres rasgos:

“Martínez es flamenco, de Burgos, bailarín. Tiene 43 años, una nariz desvergonzadamente judía, unos ojos grandes y negros de jaca jerezana, una frente atormentada de flamenco, un pelo requetepeinado de madera charolada, unos huesos que encajan mal porque, indudablemente, son de muy distintas procedencias -arios, semitas, mongoles-, y un pellejo duro y curtido como el cordobán" (Chaves Nogales, 1934/2007, p. 3).

A partir de entonces, Chaves cede la palabra y el peso del relato a su protagonista con un explícito: "Y dice Martínez, ya por su cuenta" (Chaves Nogales, 1934/2007, p. 7). Desde ese momento, Martínez relata sus sentimientos con detalle, para que el lector pudiese empatizar con él:

\footnotetext{
“Empecé a sentir náuseas. La cabeza me daba vueltas y salí tambaleándome. En el umbral piso algo blanco y escurridizo: eran dos dedos humanos que estaban pegados a las losas por un cuajarón de sangre negra. La sensación que aquello me produjo casi me hizo desvanecerme. No se me olvidará en la vida" (Chaves Nogales, 1934/2007, p. 217).
}

Martínez era un hombre errante, sentencioso, único. Al dejar hablar a Martínez, al mostrar sus prioridades y sus sentimientos, el lector conoce mejor al personaje. Se observa el fraseo propio, sentencioso, con retranca, propio de un flamenco. Chaves traduce la entonación y edita las declaraciones pero deja el tono, el color del habla del protagonista. El hecho de que aparezca una voz única también es significativo. Chaves podría haber entrevistado en profundidad a la mujer de Juan Martínez, podría haber hablado con sus compañeros, amigos... pero prefiere quedarse en el texto solo con su impresión sobre el personaje, lo que pueda vivir con él y lo que este le cuente de sí mismo y de su vida. Quizá las declaraciones y testimonios de los familiares y amigos estén de forma indirecta, ya que le han podido contar episodios de la vida de Martínez que luego Chaves pregunta al in- teresado o que simplemente señala pero sin indicar quién se lo ha contado. Es destacable la gran autoridad que se arroga Chaves en estos retratos; no hay puntos de apoyo, otras voces que corroboren su interpretación y caracterización del personaje.

La impresión que producen las palabras de Martínez y que Chaves potencia al desaparecer del relato es que el bailaor es un pícaro, un hombre que quiere sobrevivir a toda costa, que de todo lo vivido sacaba una enseñanza y que por ese motivo es un buen observador neutral de la revolución. En el fondo, tal y como señala Trapiello, la filosofía de Martínez se resume en un lugar común:

"No somos nada. Y eso es lo que Chaves persigue: una vida gris llena de avatares, de aventuras, de las vueltas que da la vida" (Suberviola y Torrente, 2013, p. 139).

Martínez es, para Cintas (2001b), "el pícaro tradicional de la novela española, un español peculiar, simbólico, que se las ingenia para vivir o sobrevivir en medio de la revolución rusa" (p. 114).

La visión que Chaves da de la revolución rusa -o su tono- fue cambiando. Sinclair (2009) dice que la llegada a España de la Segunda República no cambió estas visiones de Rusia; sin embargo, en el caso de Chaves, sí. Sinclair (2009) sostiene que Lo que ha quedado del imperio de los zares está escrito en "light and lowbrow style" (p. 124). Cambia su visión porque la situación europea y española había empeorado desde el año 28, en que escribe Chaves los primeros artículos, hasta el año 34, cuando termina el libro sobre Juan Martínez. La visita a la Unión Soviética le ayudaría a entender Europa y España. Chaves en España advierte de las consecuencias de los alzamientos revolucionarios pero no sería escuchado. Walter Benjamin, que está en Moscú el mismo año que Chaves, anota en su Diario de Moscú esta misma idea al final de su viaje:

"Por muy poco que se llegue a conocer este país, uno aprende a observar y a enjuiciar Europa con el conocimiento consciente de lo que acontece en Rusia. Eso es lo primero que le llega de Rusia a cualquier europeo inteligente. Por eso también la estancia en Rusia es, por otro lado, una piedra de toque tan precisa para el visitante extranjero. Obligará a cualquiera a elegir y precisar con exactitud su punto de vista [...]. Aquel que penetre en mayor profundidad dentro de la situación rusa se sentirá mucho menos impulsado a realizar las abstracciones a las que tan fácilmente llega un europeo" (Benjamin, 1988, pp. 142-143). 


\section{EL PERIODISMO CUANDO NO SE PUEDE ESPERAR A LA HISTORIA (CONCLUSIONES)}

Chaves no pretende escribir la historia pero la urgencia de los sucesos políticos en los años 30 obligó a muchos periodistas a hacer una información que debía responder al presente y al futuro que se avecinaba en Europa. En sus reportajes y crónicas logra mostrar mediante escenas significativas, mediante unas pocas pinceladas, el carácter de los personajes e indirectamente sus preocupaciones. Cuenta las historias como si se tratase del montaje de las escenas de una película: usando diálogo, descripción, introspección y viendo esas vidas en primer plano. Su relato está construido sobre la memoria de testigos y en esta manera de proceder el periodismo se adelanta a la microhistoria. Los reportajes muestran las huellas de un hecho pasado, pero permiten contar la historia de una realidad convertida en mito como la revolución rusa de octubre de 1917.

Xavier Pericay (2003), refiriéndose al periodismo en la Segunda República, señala a Chaves Nogales junto con Pla, Graziel y Camba como personas que, haciendo periodismo, daban una visión de la historia porque el momento -la Segunda República- Io exigía y no se podía esperar a los historiadores ( $p$. 17). Lo mismo puede decirse en el caso de la revolución rusa. No es solo que Chaves atienda a la huella que dejan los hechos históricos sino que es de ahí de donde viene en parte su intuición para interpretar lo que ve en el presente. Se reconstruye la historia (pasado) en el relato de uno de sus actores o de sus testigos y esto puede cambiar la visión de conjunto, la visión que tenemos de esa historia, de la revolución. Chaves recompone el relato de Kerenski y Miliukov de esos meses, de marzo a octubre de 1917, en Lo que ha quedado del imperio de los zares. Titula un apartado, por ejemplo, "Kerenski cuenta cómo tomaron el poder los bolcheviques" (Chaves Nogales, 2011, p. 93). En El maestro Juan Martínez que estaba allí titula las crónicas sobre los hechos de marzo en San Petersburgo "Así fue la revolución de marzo", y luego "Lo que hice en Moscú durante los diez días que conmovieron al mundo".

Chaves apostó por el periodismo, entendido como el afán de contar de la manera más veraz aquello de lo que es testigo, frente al partidismo que el momento histórico parecía exigir. Por eso, como escribió en 1937 en el prólogo de A Sangre y fuego, "cuando iba a Moscú y al regreso contaba que los obreros rusos viven mal y soportan la dictadura del proletariado que hacen la ilusión de ejercer, mi patrón me felicitaba y me daba cariñosas palmaditas en la espalda" (Chaves Nogales, 2009, p. 24) y, al mismo tiempo, "cuando al regreso de Roma aseguraba que el fascismo no ha aumentado en un gramo la ración de pan del italiano, ni ha sabido acrecentar el acervo de sus valores morales, mi patrón no se mostraba tan satisfecho de mí ni creía que yo fuese realmente un buen periodista" (Chaves Nogales, 2009, p. 24).

Chaves escribió sobre la revolución rusa por su interés informativo para la España de su época y lo hizo a través de un periodismo honrado, sin prejuicio ideológico, y alejado de la propaganda totalitaria del momento. ¿Es la revolución que a Chaves le cuentan y sobre la que escribe una revolución imaginada o real? Las crónicas y los reportajes de Chaves dieron lugar a la Rusia imaginada en España. Él elaboró esta imagen siguiendo un criterio periodístico: a través de la selección de ejemplos y de su manera de construir el relato, intentó entender el curso de la historia que habían tenido los acontecimientos y el derrotero que podía vislumbrarse en Europa con la expansión del fascismo y el nacimiento de lo que luego se llamaría estalinismo.

Chaves Nogales no busca el término medio, sino la verdad. La ecuanimidad es un resultado, no una intención. La noción de su oficio y lo vivido en el periodo de entreguerras en Europa hacen que hoy estos relatos sean vistos como imparciales. No se trata, por tanto, de una equidistancia sino de sus convicciones liberales y de su honestidad en la concepción del oficio. Advierte de lo que ocurre en Rusia cuando el sistema soviético estaba aún idealizado y lo hace sin estridencias ni dramatismos, contando lo que vivió en su viaje y lo que Martínez o los exiliados rusos blancos le contaron en París.

Chaves afirma que el horror de la guerra y de la revolución fue tan inhumano que no resulta verosímil para las gentes. Su diagnóstico en la Europa de entreguerras, sin pretender hacer historia, resultó premonitorio y lúcido porque tuvo la capacidad de entender y nombrar el origen de la barbarie o del terror en uno y otro bando. Chaves se acerca a las raíces que sustentan el horror y la inhumanidad desde el periodismo, y por este motivo el análisis que realiza y su manera de entender la profesión tienen vigencia en el siglo XXI. 


\section{BIBLIOGRAFÍA}

Avilés Farré, J. (1999). La fe que vino de Rusia. La revolución bolchevique y los españoles (1917-1931). Madrid: Biblioteca Nueva.

Benjamin, W. (1988). Diario de Moscú. Madrid: Taurus.

Chaves Nogales, M. (1929). La vuelta a Europa en avión. Un pequeño burgués en la Rusia roja. Madrid: Mundo Latino.

Chaves Nogales, M. (1929, 1 de enero). Moscú se divierte. Estampa, 52, pp. 21-22.

Chaves Nogales, M. (1929, 19 de febrero). El invierno en Rusia. Estampa.

Chaves Nogales, M. (1929, 23 de abril). Las mujeres en el régimen bolchevique. Estampa, 59, pp. 25-26.

Chaves Nogales, M. (1930, 18 de marzo) Los "flamencos" de París. Montmartre, sede de la flamenquería. Estampa, 114, pp. 10-11.

Chaves Nogales, M. (1993). Obra narrativa completa. Sevilla: Diputación de Sevilla.

Chaves Nogales, M. (2001). Obra periodística (tomo I). Sevilla: Diputación de Sevilla.

Chaves Nogales, M. (1934/2007). El maestro Juan Martínez que estaba allí. Barcelona: Libros del Asteroide.

Chaves Nogales, M. (2009). A sangre y fuego. Madrid: Austral.

Chaves Nogales, M. (2009b). Obra narrativa completa (tomos I y II). Sevilla: Diputación de Sevilla.

Chaves Nogales, M. (2011). Lo que ha quedado del imperio de los zares. Sevilla: Renacimiento.

Chaves Nogales, M. (2013). Obra periodística completa (tomos I, II y III). Sevilla: Diputación de Sevilla.
Cintas Guillén, M. I. (2001a). Introducción. En: Chaves Nogales, M. (2001). Obra periodística (tomo I). Sevilla: Diputación de Sevilla.

Cintas Guillén, M. I. (2001b). Un liberal ante la Revolución. Cuatro reportajes de Manuel Chaves Nogales. Sevilla: Secretariado de Publicaciones de la Universidad de Sevilla.

Cortés, M. A. (2006). Estampas rusas. Zaragoza: Institución Fernando el Católico.

Cruz, R. y Pérez Ledesma, M. (eds.) (1997). Cultura y movilización en la España contemporánea. Madrid: Alianza.

García-Alix, C. (2003). Madrid-Moscú. Madrid: T. Ediciones.

Giménez Caballero, E. (1928). Escritores españoles en Rusia. La Gaceta Literaria, 42 , p. 3.

Ginzburg, C. (1994). Microhistoria, dos o tres cosas que sé de ella. Manuscrits. Revista d'història moderna, 12, pp. 1342.

Hermida, C. (2002). La revolución bolchevique no fue un golpe de estado. Historia y Comunicación Social, 7, pp. 109-119.

Lippmann, W. y Merz, C. (1920). A test of the news. The New Republic, 23, pp. 1-42.

Llopis, R. (1929). Cómo se forja un pueblo. La Rusia que yo he visto. Madrid: Espaกิa.

Navarra, A. (2015). El espejo blanco. Madrid: Fórcola.

Ochoa Crespo, P. (2016). Sofía Casanova y la narración de la Revolución Soviética en ABC. Historia y Comunicación Social, 21 (2), pp. 463-476. https://doi. org/10.5209/HICS.54373

Peloille, M. (1999). Le voyage en U.R.S.S. des intelectuels espagonls (1921-1931). En
Meunier, Ph. y Soubeyroux, J. (eds.) Le vogaye dans le monde ibérique et ibéro-americain. Saint-Étienne: Publications de l'Université de Saint-Étienne, pp. 119-125.

Pérez Álvarez, Á. (2013). Manuel Chaves Nogales y el nuevo periodismo. Ámbitos. Revista Internacional de Comunicación 23, pp. 81-90.

Pericay, X. (ed.). (2003). Cuatro historias de la República. Barcelona: Destino.

Prökker H. (2012). A reservoir for understanding. Why journalism needs history as a thematic field. En Convoy, M. (ed.) How Journalism Uses History. New York: Routledge, pp. 15-32. https://doi. org/10.4324/9780203722145

Sánchez Zapatero, J. (2013). Dos visiones de la Unión Soviética: Stefan Zweig y Manuel Chaves Nogales. Acta literaria, 46, pp. 107-125. https://doi.org/10.4067/ S0717-68482013000100008

Sinclair, A. (2009). Trafficking Knowledge in Early Twentieth-Century Spain. Woodbridge: Tamesis.

Suberviola, D. y Torrente, L. F. (2013). El hombre que estaba allí. Salamanca: Libros.com.

Trapiello, A. (2010). Las armas y las letras. Madrid: Destino.

Vázquez Liñán, M. (2011). La Revolución y la guerra civil rusa en El maestro Juan Martínez que estaba allí. En: Bellido, P. y Cintas, M. I (coords.) (2011). El periodista comprometido. Manuel Chaves Nogales, una aproximación. Sevilla: Fundación Centro de Estudios Andaluces, pp. 65-83.

Villanúa, L. (1931). La Rusia inquietante. Viaje de un periodista español a la U.R.S.S. Madrid: Agencia General de Librería y Artes Gráficas.

Zweig, S. (2001). El mundo de ayer. Memorias de un europeo. Barcelona: Acantalidado. 